\title{
Bovine CD I 4 gene characterization and relationship between polymorphisms and surface expression on monocytes and polymorphonuclear neutrophils
}

\author{
Eveline M Ibeagha-Awemu ${ }^{1}$, Jai-Wei Lee ${ }^{2}$, Aloysius E Ibeagha ${ }^{1}$ and \\ Xin Zhao*1
}

Address: ${ }^{1}$ Department of Animal Science, McGill University, Ste-Anne-de-Bellevue, Quebec H9X 3V9, Canada and ${ }^{2}$ Department of Tropical Agriculture and International Cooperation, National Pingtung University of Science and Technology, Neipu, Pingtung 912, Taiwan

Email: Eveline M Ibeagha-Awemu - eveline.ibeagha-awemu@mcgill.ca; Jai-Wei Lee - joeylee@mail.npust.edu.tw;

Aloysius E Ibeagha - aloysius.ibeagha@mcgill.ca; Xin Zhao* - xin.zhao@mcgill.ca

* Corresponding author

Published: 8 August 2008

BMC Genetics 2008, 9:50 doi:10.1186/147/-2156-9-50
Received: 27 February 2008

Accepted: 8 August 2008

This article is available from: http://www.biomedcentral.com/I47I-2156/9/50

(C) 2008 lbeagha-Awemu et al; licensee BioMed Central Ltd.

This is an Open Access article distributed under the terms of the Creative Commons Attribution License (http://creativecommons.org/licenses/by/2.0), which permits unrestricted use, distribution, and reproduction in any medium, provided the original work is properly cited.

\begin{abstract}
Background: CDI4 is an important player in host innate immunity in that it confers lipopolysaccharide sensitivity to cell types like neutrophils, monocytes and macrophages. The study was aimed at characterizing the CDI 4 gene of cattle for sequence variations and to determine the effect of variations on the expression of the protein on the surfaces of monocytes and neutrophils in healthy dairy cows.
\end{abstract}

Results: Five SNPs were identified: two within the coding regions (g.Al908G and g.A23।8G, numbering is according to GenBank No. EUI48609), one in the 5' (g.CI29IT) and two in the $3^{\prime}$ (g.A260IG and g.G262IT) untranslated regions. SNP 1908 changes amino acid 175 of the protein (p.Asn 175Asp, numbering is according to GenBank No. ABV68569), while SNP 2318 involves a synonymous codon change. Coding region SNPs characterized three gene alleles $A$ (GenBank No. EUI48609), $A_{I}$ (GenBank No. EUI486IO) and B (GenBank No. EUI486II) and two deduced protein variants $A$ (ABV68569 and $\underline{A B V 68570})$ and $B(\underline{A B V 68571})$. Protein variant $A$ is more common in the breeds analyzed. All SNPs gave rise to 3 haplotypes for the breeds. SNP genotype 1908AG was significantly $(P<0.01)$ associated with a higher percentage of neutrophils expressing more CDI 4 molecules on their surfaces. The promoter region contains several transcription factor binding sites, including multiple AP-I and SPI sites and there is a high conservation of amino acid residues between the proteins of closely related species.

Conclusion: The study has provided information on sequence variations within the CDI4 gene and proteins of cattle. The SNP responsible for an amino acid exchange may play an important role in the expression of CDI4 on the surfaces of neutrophils. Further observations involving a larger sample size are required to validate our findings. Our SNP and association analyses have provided baseline information that may be used at defining the role of CDI4 in mediating bacterial infections. The computational analysis on the promoter and comparative analysis with other species has revealed regions of regulatory element motifs that may indicate important regulatory effects on the gene. 


\section{Background}

The bovine cluster of differentiation (CD) 14 is an important player in host innate immunity in that it mediates host defense against Gram-negative bacterial infections and also confers immunity against viral infections $[1,2]$. It is abundant (about 99,500 to 134,600) on the cell membrane of monocytes and to a lesser extent (about 1,900 to 4,400 ) on neutrophils (polymorphonuclear neutrophil leukocytes) [3,4]. Two forms exist, a membrane bound form (mCD14) and a soluble (sCD14) form [5]. sCD14 is known to confer lipopolysaccharide (LPS) sensitivity to cells lacking mCD14, including epithelial cells and endothelial cells $[6,7]$. Also, recombinant bovine sCD14 can sensitize mammary epithelial cells to low concentrations of LPS in vivo and in vitro thus indicating an important role of sCD14 in initiating host responses to Gramnegative bacterial infections $[8,9]$. During the periparturient period, individual variations have been noticed in the response of cows to Gram-negative and Gram-positive bacteria infections [10]. Therefore, sequence variations of the $\mathrm{CD} 14$ gene may play important roles in the presentation of CD14 molecules and thus, LPS sensitivity.

The CD14 gene of cattle was initially cloned and sequenced by Ikeda et al. [11] and recently by the bovine genome project. It is mapped to BTA 7. A SNP of human CD14 promoter has been shown to influence the activities of the gene [12]. Baldini et al. [13] reported a SNP in the human $\mathrm{CD} 14$ gene promoter involving a $\mathrm{C}$ to $\mathrm{T}$ transition at position -159 (or -260 by [14]), and associated TT homozygotes with significantly higher levels of sCD14 and lower levels of IgE in children as compared to carriers of TC or CC. Reports of association of the -159 CD14 polymorphism with several human disease conditions have emerged [15-17]. Other authors however did not find any association between this polymorphism and several diseases $[18,19]$. Despite the importance of this protein and the effect of the promoter polymorphism in humans, there is no report of sequence variations of this gene in cattle and their possible effects on circulating CD14 levels and disease susceptibility.

The objectives of this study were therefore to: (1) investigate the CD14 gene of cattle for sequence variations; (2) determine the effect of variations on CD14 expression on the surfaces of monocytes and neutrophils; and (3) use bioinformatics tools to computationally characterize the promoter region. In this study we present information on sequence variations within the CD14 gene of Canadian Holstein and Jersey cows and a possible role of one SNP in influencing the surface expression of the antigen on the surfaces of neutrophils. Furthermore, identified conserved regions of regulatory element motifs may have important regulatory effects on the gene. The results may provide baseline information that may be used in candidate gene studies aimed at defining the role of CD14 in mediating bacterial infections.

\section{Results \\ SNPs in the CDI4 gene of Canadian Holsteins and Jersey cows}

Comparison of the CD14 sequences of 106 Canadian Holsteins and 46 Jersey cows with published sequences (GenBank Nos. NW_001495367 and D84509) revealed a total of five SNPs including one in the 5 ' untranslated region (UTR) (g.C1291T, numbering is according to GenBank No. EU148609), two in the coding regions (g.A1908G and g.A2318G) and two in the 3' UTR (g.A2601G and g.G2621T) (Table 1). Four of the SNPs are transitional mutations while SNP 2621 involves the transversion of guanine to thymine. SNP 1908 is responsible for a non-synonymous codon change in amino acid 175 of the protein, from Asn (aac) to Asp (gac), while SNP 2318 results in a synonymous codon change without a change in amino acid 311 (Pro, cca vs ccg) of the protein. The coding region SNPs characterizes three gene alleles $A$ $\left(\mathrm{A}_{1908} \mathrm{~A}_{2318}\right)$ (GenBank No. EU148609), $A_{1}\left(\mathrm{~A}_{1908} \mathrm{G}_{2318}\right)$ (GenBank No. EU148610) and $B\left(\mathrm{G}_{1908} \mathrm{G}_{2318}\right)$ (GenBank No. EU148611) and two deduced protein variants A (Asn175) $\left(\mathrm{A}_{1908} \mathrm{~A}_{2318}\right.$, GenBank No. ABV68569 or $A_{1908} G_{2318}$, GenBank No. ABV68570) and B (Asp175) $\left(\mathrm{G}_{1908} \mathrm{G}_{2318}\right.$, GenBank No. ABV68571). Protein variant A is more common in the breeds analyzed with a frequency of $88.6 \%$ in Holsteins and fixed in Jerseys (Table 1). Within protein variant $\mathrm{A}$, gene allele $A_{1}$ occurred at a very high frequency $(80.2 \%)$ in Jerseys. The non-coding SNPs occurred at about equal magnitudes in Holsteins while the frequencies of $\mathrm{T}_{1291}, \mathrm{G}_{2601}$ and $\mathrm{T}_{2621}$ were above $80 \%$ in Jerseys.

Comparison of deduced protein sequences with reported CD14 protein sequences for cattle (UniProt AAD32215 and UniProt NP_776433) revealed a further amino acid difference, 209Ser $\rightarrow$ Thr. Further comparisons revealed that amino acid 175Asn is conserved in cattle, buffalo (UniProtKB ABE68724), goat (UniProtKB ABE68725) and sheep (UniProtKB NP_001070677) while Asp is present at this position in cattle variant $B$.

\section{Haplotye structure of the breeds}

Considering the five SNPs identified and the genotype information of all individuals sequenced, the program PHASE V2.2.1 determined a total of four potential haplotype combinations (CAAAG- $\mathrm{C}_{1291} \mathrm{~A}_{1908} \mathrm{~A}_{2318} \mathrm{~A}_{2601} \mathrm{G}_{2621}$, CGAAG, TGGGT, TAGGT) in the analyzed breeds. TGGGT was absent in Jersey while CGAAG was absent in both populations. The gene alleles $A 1$ and $B$ were observed from the sequencing data to be associated with SNPs $\mathrm{T}_{1291}, \mathrm{G}_{2601}$ and $\mathrm{T}_{2621}$ while allele $A$ was associated with $\mathrm{C}_{1291}, \mathrm{~A}_{2601}$ and $\mathrm{G}_{2621}$ therefore giving rise to three actual 
Table I: SNPs, gene alleles, protein variants, haplotypes and their frequencies in the analyzed breeds

\begin{tabular}{ccc}
\hline Parameter & Holstein $(\mathrm{n}=106)$ & Jersey $(\mathrm{n}=43)$ \\
\hline CI29IT* & & \\
C & 0.658 & 0.198 \\
$T$ & 0.342 & 0.802 \\
AI908G & & \\
$A$ & 0.886 & 1.000 \\
$G$ & 0.114 & - \\
A23I8G & & \\
$A$ & 0.658 & 0.198 \\
$G$ & 0.342 & 0.802 \\
A260IG & & \\
$A$ & 0.658 & 0.198 \\
$G$ & 0.342 & 0.802 \\
G262IT & & \\
$G$ & 0.658 & 0.198 \\
$T$ & 0.342 & 0.802 \\
Gene alleles (haplotypes) & & \\
A (CAAAG) & 0.658 & 0.198 \\
$A_{1}(T A G G T)$ & 0.228 & 0.802 \\
B (TGGGT) & 0.114 & - \\
Protein variants & & 1.000 \\
A or ** 175Asn & 0.886 & - \\
B or I75Asp & 0.114 &
\end{tabular}

*SNP Numbers are according to GenBank No. EUI48609

** Amino acid residue numbering is according to GenBank No. ABV68569

haplotypes (TAGGT, TGGGT and CAAAG) in the analyzed populations (Table 1). The frequency of the haplotype associated with allele $A$ (CAAAG) was highest $(65.8 \%)$ in Holsteins while the haplotype associated with allele $A_{1}$ (TAGGT) was highest in Jerseys (80.2\%) (Table 1).

\section{Effects of CDI4 genotypes on the expression of CDI4 on the surfaces of monocytes and neutrophils}

Whole blood from healthy Holstein cows (animals showing no outward symptoms of infection and farm record indicating milk somatic cell counts below 200,000 cells/ $\mathrm{ml}$ ) with different CD14 genotypes were incubated with fluorescein isothiocyanate (FITC)-labeled mouse antihuman CD14 antibody to determine the effects of genotypes on the expression of CD14 antigens on the surfaces of monocytes and neutrophils. The results are presented in Figure 1 and Table 2. In Figure 1, a higher percentage of gated monocyte cells were found in the LogFITC region labeled M2 ( $\log 10^{2}$ and above) which indicates a higher fluorescence intensity coming from cells with the most CD14 antigens on their surfaces and termed the high expression region. On the other hand, more neutrophils were in the $\mathrm{M} 1$ or low expression region $\left(\log 10^{1}\right.$ to $\left.10^{2}\right)$. The mean channel fluorescence (MCF) intensities (for all cows) observed for the gated regions were $\mathrm{M} 1=32.04$ (range 16.67 - 65.18), M2 = 288.97 (149.85 - 566.47) and M3 $=201.44(73.57-437.56)$ for monocytes and M1 $=22.76(16.20-35.52), \mathrm{M} 2=267.33(148.26-536.87)$ and M3 = $34.76(19.49-60.83)$ for neutrophils. As presented, the M3 (M1 + M2) MCF intensity for monocyte was higher than for neutrophils. SNP A1908G that changes amino acid 175Asn to Asp, and thus protein A to $B$, is significantly $(P<0.01)$ associated with a higher number of neutrophils in the $\mathrm{M} 2$ or higher expression zone. $7.26 \%$ of gated neutrophils from cows of genotype 1908 AG were found in M2 as compared to $4.36 \%$ from cows of genotype 1908AA (Table 2). In the M1 zone, the percentage of neutrophils from cows of both genotypes was the same. For monocytes, a higher number of total

Table 2: Effects of CDI4 genotypes on its expression (in \%) on the surfaces of monocytes and neutrophils in Holstein cows $(n=64)$

\begin{tabular}{|c|c|c|c|c|c|c|c|c|}
\hline \multirow[t]{2}{*}{ Parameter } & \multirow[t]{2}{*}{ Genotypes } & \multirow[t]{2}{*}{ No. } & \multicolumn{3}{|c|}{ Monocytes } & \multicolumn{3}{|c|}{ Neutrophils } \\
\hline & & & *Low & High & Total & Low & High & Total \\
\hline \multirow[t]{3}{*}{$* * \mathrm{Cl} 29 \mathrm{IT}$} & $\mathrm{CC}$ & 28 & $29.57 \pm 1.54$ & $57.00 \pm 1.81$ & $86.57^{a} \pm 0.96$ & $73.25 \pm 2.52$ & $4.48 \pm 0.62$ & $77.74 \pm 2.73$ \\
\hline & CT & 30 & $28.25 \pm 1.48$ & $61.26 \pm 1.75$ & $\left.89.5\right|^{b} \pm 0.93$ & $76.21 \pm 2.43$ & $5.54 \pm 0.60$ & $81.75 \pm 2.64$ \\
\hline & TT & 6 & $32.02 \pm 3.32$ & $58.94 \pm 3.91$ & $90.97^{b} \pm 2.07$ & $81.57 \pm 5.43$ & $4.11 \pm 1.34$ & $85.68 \pm 5.91$ \\
\hline \multirow[t]{2}{*}{ AI908G (Asn I75Asp) } & $\mathrm{AA}$ & 51 & $29.10 \pm 1.14$ & $59.12 \pm 1.36$ & $88.22 \pm 0.74$ & $75.25 \pm 1.88$ & $4.36^{\mathrm{A}} \pm 0.43$ & $79.60 \pm 2.03$ \\
\hline & AG & 13 & $29.49 \pm 2.26$ & $59.39 \pm 2.70$ & $88.88 \pm 1.47$ & $76.09 \pm 3.72$ & $7.26^{B} \pm 0.86$ & $83.35 \pm 4.03$ \\
\hline \multirow[t]{5}{*}{ Haplotypes } & CAAAG, CAAAG & 28 & $29.57 \pm 1.56$ & $57.00 \pm 1.82$ & $86.57^{a} \pm 0.97$ & $73.25 \pm 2.55$ & $4.48^{a} \pm 0.59$ & $77.74 \pm 2.78$ \\
\hline & CAAAG, TAGGT & 20 & $27.75 \pm 1.84$ & $62.46 \pm 2.16$ & $90.21^{b} \pm 1.14$ & $77.36 \pm 3.01$ & $4.45^{a} \pm 0.70$ & $81.81 \pm 3.28$ \\
\hline & CAAAG, TGGGT & 10 & $29.24 \pm 2.60$ & $58.85 \pm 3.05$ & $88.09^{a} \pm 1.61$ & $73.90 \pm 4.26$ & $7.73^{b c} \pm 0.98$ & $81.63 \pm 4.65$ \\
\hline & TAGGT, TGGGT & 3 & $30.33 \pm 4.75$ & $61.18 \pm 5.56$ & $91.5 \mathrm{I}^{\mathrm{a}} \pm 2.95$ & $83.41 \pm 7.78$ & $5.68^{\mathrm{ab}} \pm 1.80$ & $89.08 \pm 8.48$ \\
\hline & TAGGT, TAGGT & 3 & $33.72 \pm 4.75$ & $56.72 \pm 5.56$ & $90.42^{a} \pm 2.95$ & $79.73 \pm 7.78$ & $2.55^{\mathrm{a}} \pm 1.80$ & $82.28 \pm 8.48$ \\
\hline
\end{tabular}

a, b, c or A, BMeans for each parameter and within the same column differ significantly. a, b, c indicates significance $(P<0.05)$ with non adjusted means while A, B indicate significance with both non-adjusted means and when Scheffe's adjustments were applied to means $(P<0.01)$. SNPs I29I, 23I8 and $260 \mathrm{I}$ are in 100\% linkage disequilibrium and possess the same information, like wise are gene alleles and haplotypes. Only values for SNPI29I and haplotypes have been represented in the table.

*Low indicates the percentage of cells in the region of Log $10^{1}$ to $10^{2}$, high $>\log 10^{2}$ and total, all cells stained.

**SNP numbering is according to GenBank No. EUI48609 and amino acid residue numbering is according to GenBank No. ABV68569. 


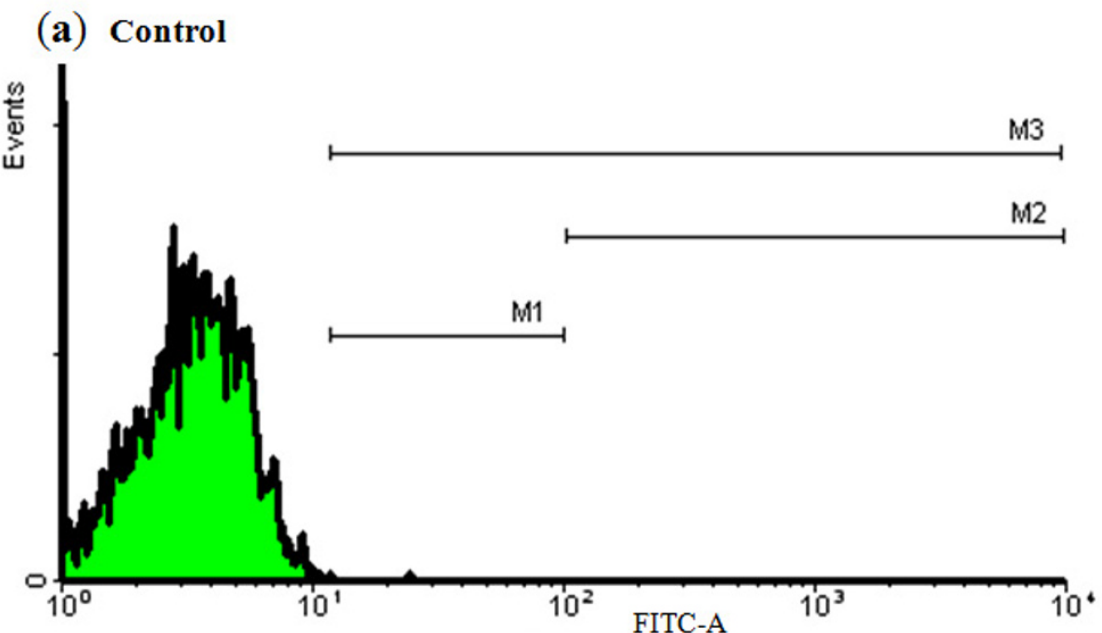

\section{(b) Stained monocytes}

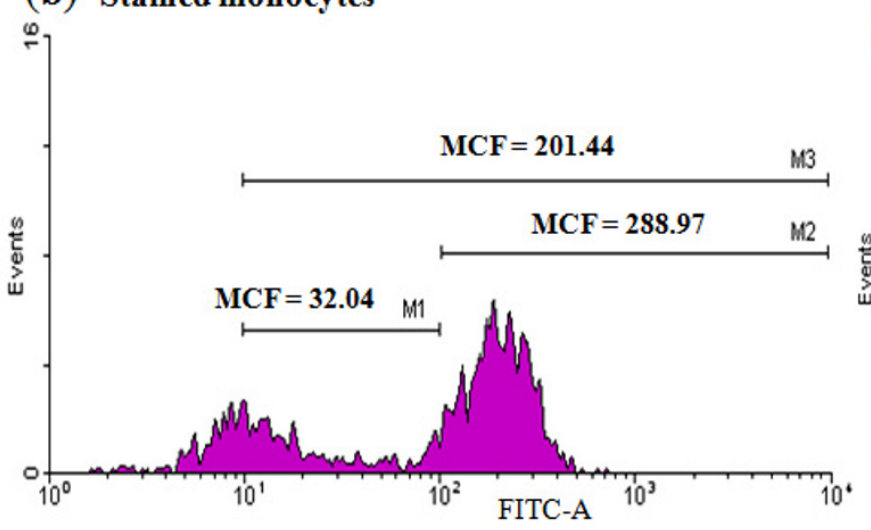

(c) Stained neutrophils

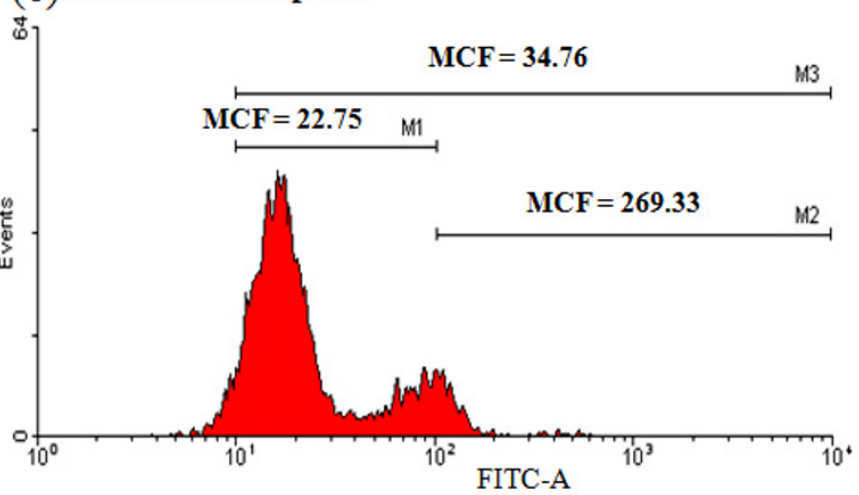

Figure I

Flow cytometyric analyses of relationship of surface expression of CDI4 on monocytes and neutrophils with CDI4 genotypes. Cells were stained with fluorescein isothiocyanate (FITC)-labelled mouse anti human CDI4 antibody and 20,000 events were gated and analyzed with Windows Multiple Document Interface for flow cytometry (WinMDI) software version 2.8. (a) Histogram showing a control sample that was not stained with antibody and occupies the Log $10^{\circ}$ to $10^{1}$ region and known as the control zone. $\mathrm{MI}\left(\mathrm{Log} I \mathrm{O}^{1}\right.$ to $\left.10^{2}\right)$ is the zone of low expression or lower fluorescence zone indicating lower number of CDI4 antigens on cells, $\mathrm{M} 2$ ( $\mathrm{Log} 1 \mathrm{O}^{2}$ and higher) is the zone of higher fluorescence emitted by a higher rate of absorption by more CDI 4 antigens on cells and M3 is the total area of expression. (b) Histogram showing stained monocytes with a higher percentage of cells in $\mathrm{M} 2$ and a higher overall MCF intensity of 201.44 as compared to 34.76 for polymorphonuclear neutrophils; (c) Histogram showing stained polymorphonuclear neutrophils with a higher percentage of cells in MI.

cells stained was observed for 1291CT $(\mathrm{P}<0.05)$ and the other genotypes (2318AG, 2601AG and 2621GT) in perfect linkage disequilibrium with C1291T but this difference disappeared when Scheffe's adjustments was applied to means. A similar result was recorded for haplotypes.

\section{Characterization of CDI4 promoter and comparative analysis ofCD 14 proteins}

The CD14 sequence analyzed in this study is made up of 2630 bps with a 1213 bp promoter (Figure 2), two exons and one intron (GenBank No. EU148609). With the use of bioinformatics tools and published information in the literature, we were able to identify putative transcription factor binding sites (TFBSs) (with 100\% match against searched data bases) on the bovine CD14 promoter. The putative TFBSs described here are, in particular, those already demonstrated to control the expression of the gene in human and rat. The putative motifs are shown in Figure 2 (boxed) and include amongst others 9 PU.1, 7AP1, 5 SP1, 4 C/EBP, 3 c-Myb and 2 AP-2 sites.

We also searched for conserved regulatory motifs in the core promoters of the CD14 genes of different species (cattle, human, mouse, rat and pig) through a query in the 


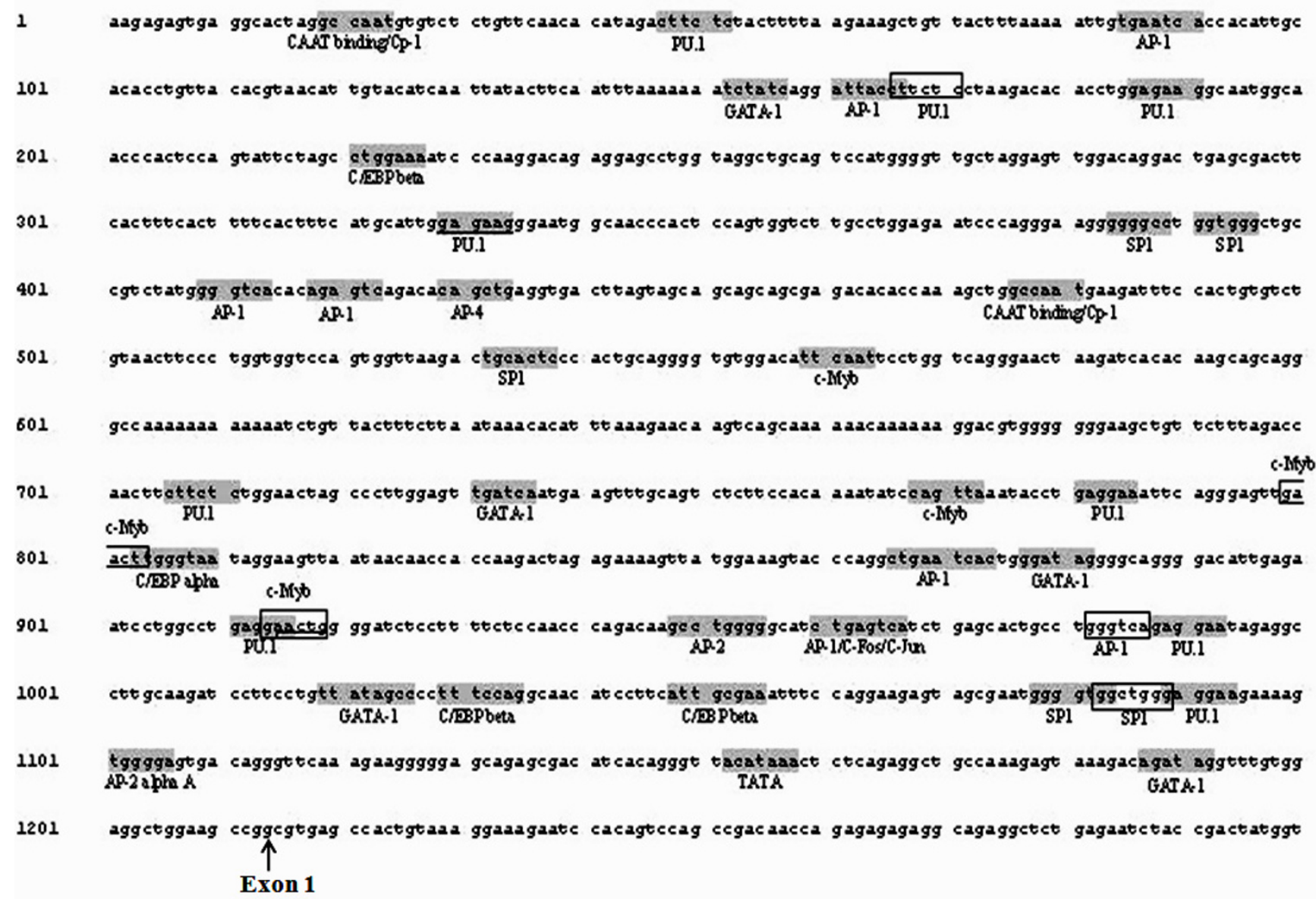

Figure 2

Putative transcription factor binding sites (with $100 \%$ match) on the bovine CDI4 promoter (I2I 3 bps). Recognition sequences are shaded. The rectangle is used where recognition sequences overlap. The arrow points to the first nucleotide of exon I at position I2I4. Numbering is according to GenBank No. EUI48609.

NSITEM data base http:linux1.softberry.coberry.phtml?topic=nsitem\&groa ms\&sub group=promoter. The results indicated a total of 63 motifs of 50 regulatory elements (REs) that were conserved in the analyzed breeds with zero to 3 bp mismatches (Figure 3). Nine of the motifs representing 6 REs including C/EBP and Spi-1/PU.1 were conserved in all the species while 4 motifs of 3 REs including AP1 and C/EBPalpha were conserved in 4 species including cattle (Figure 3 ). Furthermore, $60.30 \%$ (38) of the motifs were conserved between cattle and at least two other species. Sequence alignment of the same region revealed a perfect conservation, both in nucleotide number and orientation of the TATA box in cattle, human, mouse and rat (data not shown). The TATA box of pig differed from the others by only one bp mismatch.

Further, we checked the degree of conservation between the CD14 proteins of cattle with those of different species.
Protein sequences compared were those deduced in this work, variants A ( $\underline{A B V 68569})$ and B (ABV68571), other published bovine sequences UniProt: BAA21517, AAD32215 and NP_776433, protein sequences of buffalo ( $\underline{\mathrm{ABE} 68724})$, goat $(\underline{\mathrm{ABE68725}})$, sheep ( $\mathrm{NP}$ 001070677), pig ( $\underline{\text { AAY98033) }}$, mouse (CAA32166) , rat (NP 068512) and human variant 1 (NP 001035110) and 2 (NP_000582). The analysis revealed extensive conservations in the amino acid composition and structure. For the bovine proteins, the sequence of ABV68569 is the same as $\underline{B A A 21517}$ while AAD32215 and NP 776433 differed from $\mathrm{ABV} 68569$ by having amino acid 209 changed from Ser to Thr. This indicates the presence of a further CD14 protein variant in cattle here named $\mathrm{C}$. Furthermore, the amino acids of the CD14 proteins of buffalo, sheep and goat shared high conservation rates of $97.05 \%, 95.17 \%$, and $87.40 \%$ respectively, with the bovine ABV68569, followed by pig (76.94\%) (Figure 4 ). The rate of amino acid conservation of bovine A variant was less with the human 


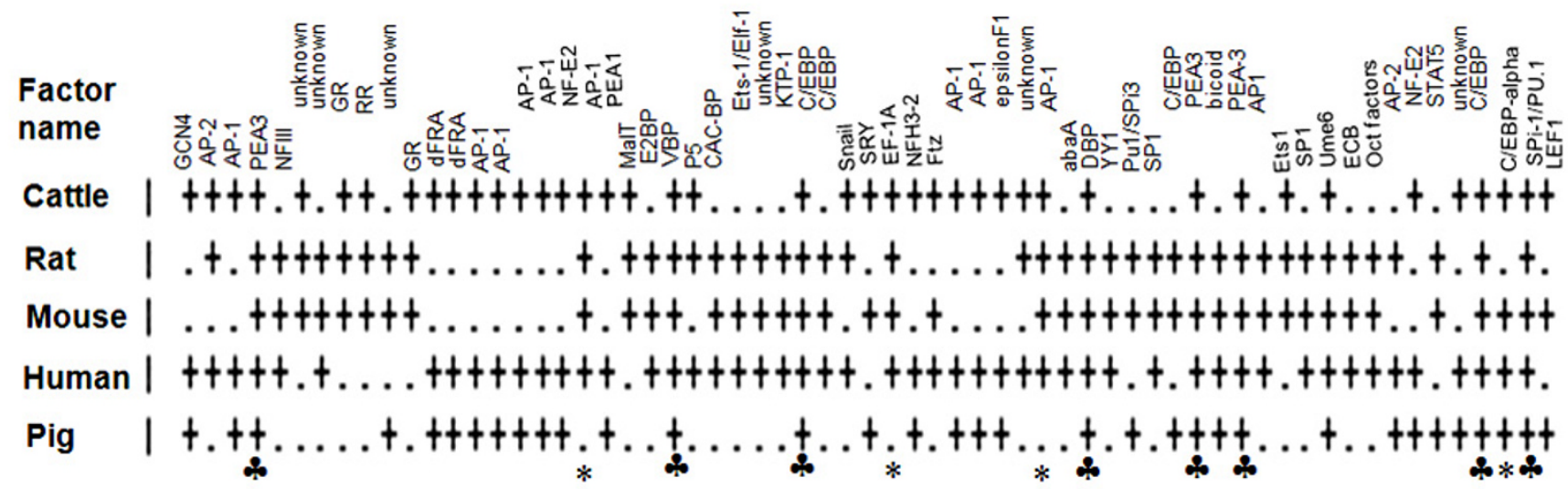

\section{Figure 3}

Conserved motifs of regulatory elements in the core promoter regions (about 500 bps) of cattle (GenBank No. EUI48609), rat (GenBank No. AF087944), mouse (GenBank No. XI 3987), human (GenBank No. U00699) and pig (GenBank No. DQ079063). + indicates the presence of a motif and $\bullet$ its absence. * indicates motifs that are conserved in all five species and * in four species including cattle. A maximum of three base pair mismatches was allowed.

(72.39\%), mouse $(61.66 \%)$ and rat $(60.59 \%)$ proteins. While bovine, buffalo, goat, sheep and pig proteins are made up of 373 amino acids, the human protein has two more, and the rat and mouse have one more and seven less animo acids, respectively. The signal peptide, made up of the first 20 amino acids, was highly conserved (only one amino acid difference, 14 Ser to Pro) between the bovine and buffalo/goat/sheep proteins. The difference between cattle and the pig was 4 amino acids while being highly diverged with human, mouse and rat (7 to 12 amino acid differences). These relationships were further represented phylogenetically (Figure 4). As depicted in Figure 4, three main groups were evident; the rat and mouse proteins in group one (bootstrap value 100), the human proteins in another group (bootstrap value 100) while members of the Artiodactyla order (bovine, buffalo, goat, sheep) and pig formed a group of their own (bootstrap value 99). In the third group, the pig formed an outcrop of its own, while a closer relationship was visible between cattle and buffalo on the one hand (bootstrap value 72) and, goat and sheep on the other hand (bootstrap value 78 ).

\section{Discussion}

We report here sequence variations of the bovine CD14 gene of Canadian Holstein and Jersey cows, through genomic DNA sequencing and computational analysis of the promoter. A gene is made up of both coding and noncoding regions which are all important in its expression and functionality. The complete description of a gene must therefore contain necessary information about the protein coding regions [20] and non-coding regions. The CD14 gene is an important component in host immunity
$[1,8]$ and detailed information on its structure and sequence variations as shown in this study may provide further insight into its mode of action.

The coding region SNPs in our study and comparative analysis of our sequences with published sequences show that the CD14 gene of cattle codes for three putative CD14 proteins-A (GenBank No. ABV68569 and ABV68570), B (GenBank No. ABV68571) and C (UniProt AAD32215 and UniProt NP_776433), with A and B described herein. The A variant, fixed in Jerseys and with a high frequency of $88.6 \%$ in Holsteins, may be the original wild type allele for the gene. Furthermore, the sequence of UniProt BAA21517 is similar to variant A and the haplotyes that contain the A variant SNPs are at the highest frequencies in the studied breeds. The other variants may therefore be the result of recent mutational events. Further three SNPs described in the $5^{\prime}$ and 3'UTRs and one synonymous SNP in the coding region of the gene indicates a higher sequence variation for the gene in Canadian Holsteins than Jerseys.

The variations, both in the coding and non-coding regions of the gene may affect the surface expression of CD14 molecules on monocytes and neutrophils. Interestingly, the coding region SNP that gave rise to the $\mathrm{B}$ variant of the protein (g.A1908G or p.Asn175Asp) had the greatest effect by being associated with the highest number of neutrophils expressing more CD14 molecules on their surfaces. It is well known that, monocytes express more CD14 receptors on their surfaces, about 99,500 to 134,600 as compared to 1,900 to 4,400 for neutrophils (3). This difference was clearly shown by the pattern of 


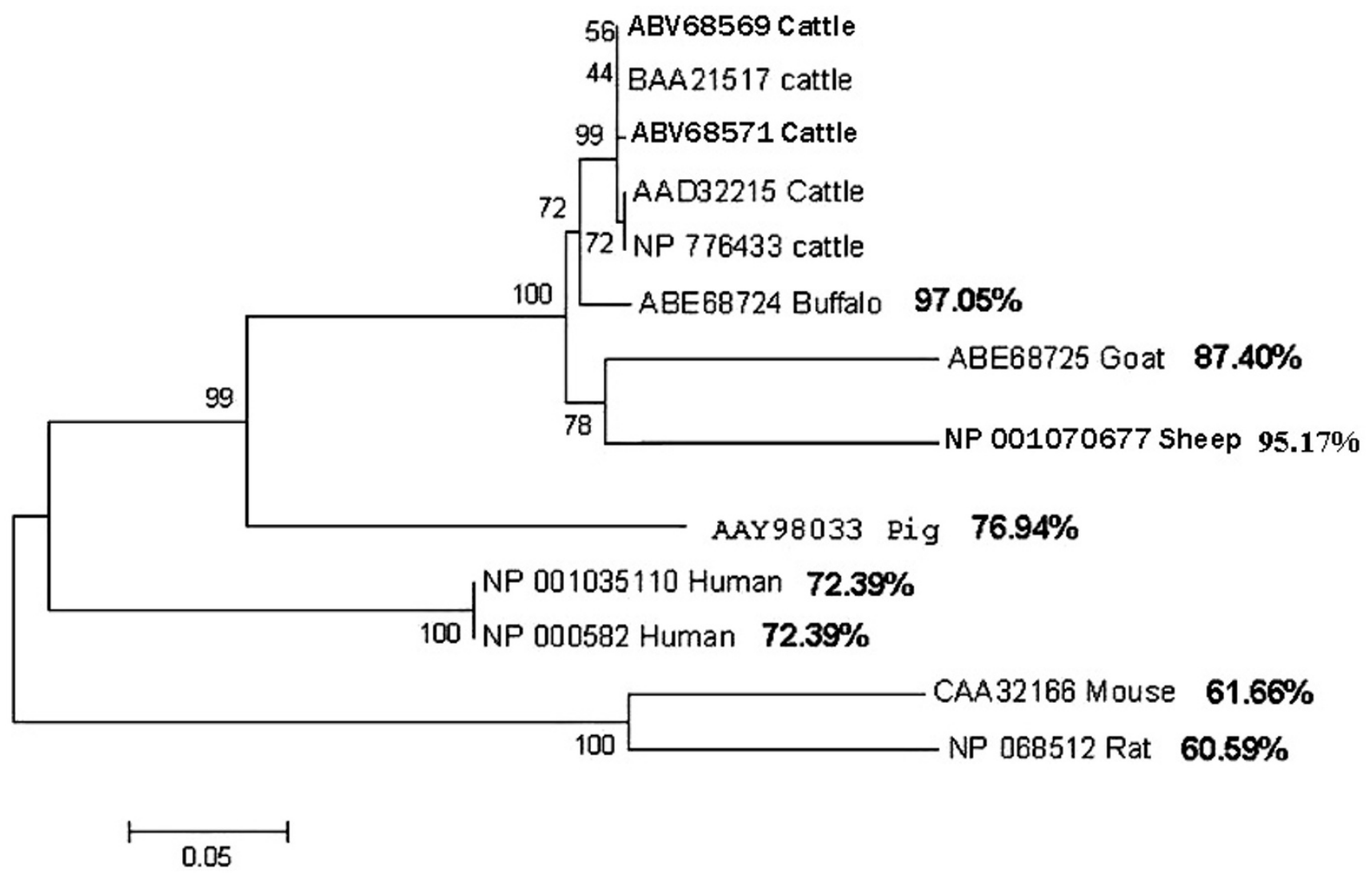

Figure 4

A Neighbor-joining dendrogram of the phylogenetic relations among the CDI4 proteins of cattle, buffalo, goat, sheep, pig, human, mouse and rat. Species common names are preceded by their GenBank numbers. The degree of amino acid conservation between the bovine proteins and other species is represented in percentages. On the nodes are percent bootstrap values.

expression depicted in Figure 1 whereby, more monocytes were recorded in the M2 gated zone (region of higher expression) and more neutrophils in the M1 zone (lower expression). These results suggest that, the characteristic B protein SNP or g.A1908G may play a role in cell surface expression of CD14 on neutrophils. Also, the SNP in the 5 'UTR region could be important in influencing the expression of this receptor on monocytes. Our data was however based on a small sample size necessitating further verifications on a larger scale. Neutrophils form a major line of defense against bacterial infections and their effectiveness depends on their availability at the site of infections. For Gram-negative bacterial infections, the CD14 molecule confers LPS sensitivity to neutrophils [4], which is necessary to initiate host immune responses. The complex of TLR4, CD14 and myeloid differentiation protein 2 , enhanced by the presence of LPS binding protein is crucial in LPS signaling; leading to the release of cytokines [21-23].
Even though no promoter polymorphism was detected in this study, a promoter polymorphism of the gene in human is a risk factor in several diseases [15-17]. The promoter region in bovine may probably be under strong purifying selection which may explain the lack of SNPs in this region. This is a positive factor considering the important role of the gene in mediating Gram-negative bacteria attack and the possible effect of the 1908 SNP on the abundance of the molecule on the surfaces of neutrophils. Determination of the roles of the individual SNPs and haplotypes on the activities of the gene under disease conditions will further shed more light on their biological significance.

Our analysis on promoter characterization indicates that part of the exon 1 reported by Ikeda et al. [11] constitutes the promoter. Since evolutionary pressures lead to the conservation of important non-protein-coding regulatory regions, including transcription factor binding sites 
(TFBs) across closely related species, identification of TFBs described in the CD14 genes of human [24] and rat [25] in the present study was expected. In particular, the perfect conservation of the TATA box, 9 motifs of 6 REs motifs across cattle, human, rat, mouse and pig and 4 other motifs across at least 4 of these species including cattle shows common regions in the core promoter that act together in the same biological context to control the expression of gene products and functions. In our study, up to 5 SP1 and 8 AP1 sites (with no bp mismatch) were identified which may indicate possible roles in controlling the expression of the gene as demonstrated in the rat and humans $[24,25]$. In the rat, Lui et al. [25] through mobility shift assays demonstrated that the SP1 and AP1 elements located respectively at positions -836 and -270 were required for basal promoter activity in liver cells. Also, Zhang et al. [24] showed that the SP1 transcription factor bound to three different regions of the human CD14 promoter and that a mutation of the major SP1 binding site decreased tissue specific promoter activity. One of the AP1 sites in our study, also shared by c-Fos and c-Jun (position 960-967, Figure 2), is similar to an AP1 site in rat promoter were JunD and Fra-2 proteins have been shown to bind [25]. This site is also thought to transactivate the basal expression of the gene [25]. This site in the mouse also plays a major role in the expression of the CD14 gene in macrophages [26]. Furthermore, three motifs of PEA3 interestingly were conserved in the promoters of all species studied. PEA3 belongs to the ETS transcription factor super family and is known to appear on the promoters of many cellular genes, including HER2/neu [27] and CD226 antigen [28]. Conservation of C/ EBP or CCAAT/enhancer binding proteins motifs in the studied species may be explained by their involvement in many aspects of cell growth. The high conservation of the amino acids of the proteins of bovine, buffalo, sheep and goat proteins was reflected in the tree of their phylogenetic relationships and is in line with other studies that found a high rate of conservation of genes and protein coding nucleotide positions between bovine, sheep and goat genes $[29,30]$. This further supports the fact that information from the sequencing of the bovine genome will greatly enhance studies in other very closely related species.

\section{Conclusion}

Overall, this study provides information on sequence variations of the CD14 gene of Canadian Holstein and Jersey cows. The identified variations and association data have provided information that may shade more light on cell surface expression of CD14 by neutrophils, which are needed to control bacterial infections. Further data on the biological significance of the mutations is however necessary. Our computational analysis highlighted on the regu- latory element motifs present in the promoter region of the gene. The comparative analysis with other species revealed conserved regions of regulatory element motifs that may have important regulatory effects on the gene.

\section{Methods \\ Animals and genomic DNA extraction}

Genomic DNA was extracted from the blood of 106 Canadian Holstein cows kept at the Howard Webster CentreMacdonald Teaching Farm, McGill University and the milks of 46 Jersey cows enrolled in the Quebec Dairy Production Centre of Expertise program http://www.val acta.com using Nucleospin Blood Mini Kit (MachereyNagel Inc. Easton, PA) as described by the manufacturer. In the case of milk DNA isolation, the manufacturer's protocol was slightly modified. Milk samples were initially centrifuged at $13000 \mathrm{rpm}$ for $15 \mathrm{~min}$ at $4{ }^{\circ} \mathrm{C}$ to remove excess fat before proceeding with the manufacturer's protocol.

\section{PCR amplification and sequencing}

Four primer pairs were designed with Invitrogen's OligoPerfect $^{\mathrm{TM}}$ software (Invitrogen, Canada Inc., Burlington, ON, Canada) based on GenBank No. NW_001495367 and used to amplify overlapping regions covering the whole Bos taurus CD14 gene (Table 3). Invitrogen synthesized the primers.

PCR reactions with all primer pairs were each carried out in a total volume of $45 \mu \mathrm{L}$ containing $50 \mathrm{ng}$ DNA, 0.25 mM dNTPs, 2.0 to $2.5 \mathrm{mM} \mathrm{MgCl}_{2}$ (Table 3), $10 \mu \mathrm{M}$ of each primer, 2 units Tag DNA polymerase (Fermentas Life Sciences, Burlington, ON, Canada) and $1 \times$ Taq buffer. The cycling conditions, with PTC- $100^{\mathrm{TM}}$ thermal cycler (MJ Research, Inc., Watertown, MA, USA) included an initial denaturation for $2 \mathrm{~min}$ at $94^{\circ} \mathrm{C}$ followed by 30 cycles comprising $30 \mathrm{sec}$ at $94^{\circ} \mathrm{C}, 30 \mathrm{sec}$ at $60^{\circ} \mathrm{C}, 50 \mathrm{sec}$ at $72^{\circ} \mathrm{C}$, and a final elongation for $5 \mathrm{~min}$ at $72^{\circ} \mathrm{C}$. Both directions of amplified PCR products were sequenced by McGill University/Genome Quebec Innovation Centre using the big dye termination technique and an ABI 3700 sequencer.

\section{Sequence analysis}

Sequences were processed with Chromas, version 1.45 http://www.technelysium.com.au/chromas14x.html)

and comparison with other published sequences was done with the multiple sequence alignment program with hierarchical clustering, Multalign http://bioinfo.genop ole-toulouse.prd.fr/multalin/multalin.html. CD14 protein sequences of different species (cattle, buffalo, goat, sheep, pig, man, mouse and rat) were aligned or processed with MEGA3.1 software [31] and phylogenetic relationships also constructed with the same software. 
Table 3: Primers used in the amplification of the whole bovine CDI4 gene and other PCR conditions

\begin{tabular}{|c|c|c|c|}
\hline Primer & *Primer sequence & $\mathrm{MgCl}_{2}$ concentration & Amplicon size (bp) \\
\hline BoCDI4.83330F & 5'ATT ACC TTC TTC TGC ACC TCC A 3' & $2.5 \mathrm{mM}$ & 1578 \\
\hline BoCDI4.84907R & 5' GGC AGC CTC TGA GAG TTT ATG T 3' & & \\
\hline BoCDI4.84746F & 5' CTT CCT GTT ATA GCC CCT TTC C 3' & $2.5 \mathrm{mM}$ & 832 \\
\hline BoCDI4.85577R & 5' CAC GAT ACG TTA CGG AGA CTG A 3' & & \\
\hline BoCDI4.85456F & 5' GGG TAC TCT CGT CTC AAG GAA C 3' & $2.0 \mathrm{mM}$ & 825 \\
\hline BoCDI4.86280R & 5' CTG AGC CAA TTC ATT СCT CTT C 3' & & \\
\hline BoCDI4.8608IF & 5' ACC TGA CTC TGG ACG GAA ATC 3' & $2.0 \mathrm{mM}$ & 747 \\
\hline BoCDI4.86827R & 5' TAC AGG AGA GCA ACC CTG AAA 3' & & \\
\hline
\end{tabular}

*Primers were designed based on GenBank No. NW 00I495367. Numbers preceding F or R in primer names represent their positions on the reference sequence.

\section{Computational characterization of the bovine CD/4 promoter}

The promoter region was analyzed for the presence of putative transcription factor-binding sites using the combined search query against the TRANSFAC database with a maximum allowable string mismatch of 10\% [[32]; http://www.cbil.upenn.edu/cgi-bin/tess/tess]. The combined search query option was used to take advantage of the full power of combined string and weight matrix searching, pre-filtering of factors, significance p-values, and new information in new databases. Particular attention was paid to binding sites already proven to be of significance in regulating the CD14 gene of other species and other common binding sites in mouse and human.

\section{Identification of conserved motifs of regulatory elements in the non-coding regions of the CDI4 gene of cattle and other species}

Since regions of conserved non-coding sequences between closely related or divergent species are likely to have common functional roles, we searched the region, about 500 bps of the core promoters of cattle (this study or GenBank No. EU148609), human (GenBank No. U00699), mouse (GenBank No. X13987), rat (GenBank No. AF087944) and pig (GenBank No. DQ079063) for described conserved regulatory element (RE) motifs against the NSITEM data base http://linux1.soft berry.coberry.phtml? topic $=$ nsitem \&group $=$ proams\&sub oup=promoter. These species were chosen because of the availability of complete or partial promoter sequence information.

\section{Flow cytometry}

Flow cytometry was used to study the effects of identified CD14 SNPs on the expression of CD14 on the surfaces of neutrophils and monocytes in healthy cows. Blood was collected from the caudal vein of 64 Holstein cows with known CD14 genotypes by venipuncture into vacutainer tubes coated with heparin anticoagulant (BD Biosciences,
Franklin Lakes, NJ, USA). After collection, samples were stored on ice and analyzed within four hours. One hundred microlitre of heparinized whole blood was placed in a $12 \times 75 \mathrm{~mm}$ flow cytometric (FCM) tube and incubated with $10 \mu \mathrm{L}$ of fluorescein isothiocyanate (FITC)-labeled mouse anti human CD14 antibody (ABD Serotec Inc., Raleigh, NC, USA). This was mixed (Barnstead Thermolyne, Dubuque, IOWA, USA) thoroughly and incubated at room temperature on an orbitron rotator (Boekel Ind. Inc., PA, USA) for 30 minutes. Lysis and fixation of erythrocytes was done by adding $2 \mathrm{~mL}$ of lysing solution (PHAGOTEST ${ }^{\circledast}$ Kit, Orpegen Pharma, Heidelberg, Germany) to the mixture. This was mixed gently, incubated for 20 minutes on an orbitron rotator at room temperature and centrifuged at $250 \mathrm{~g}$ for 5 minutes at $4^{\circ} \mathrm{C}$. The supernatant was aspirated leaving approximately $400 \mu \mathrm{L}$ of cells in the FCM tube. This was washed with $3 \mathrm{~mL}$ of Dulbecco's phosphate buffered saline (DPBS) $\mathrm{pH} 7.2$ (Life Technologies) by centrifuging at $250 \mathrm{~g}$ for 5 minutes at $4{ }^{\circ} \mathrm{C}$. The supernatant was aspirated as described above and the cells resuspended in $1 \mathrm{~mL}$ of DPBS and analyzed by flow cytometry (Becton Dickinson Immunocytochemistry Systems, San José, CA, USA) within 30 minutes. Excitation of samples was at $488 \mathrm{~nm}$; with FITC fluorescence measured at $525 \mathrm{~nm} \pm 10 \mathrm{~nm}$. Acquisition was stopped when 20,000 gated events were collected in the fluorescence cell count histogram. Gating of monocytes and polymorphonuclear leukocytes was based on forward scatter and side scatter dot plots by encircling the populations with amorphous regions. All parameters were recorded with logarithmic amplifications. List mode flow cytometric data from 20,000 events were stored and processed with the Windows Multiple Document Interface for flow cytometry (WinMDI) software version 2.8 (Joseph Trotter, The Sripps Research Institute, http://facs.scripps.edu/soft ware.html) on a personal computer.

The viability of neutrophils and monocytes in whole blood was determined by propidium iodide (PI) exclu- 
sion ( $50 \mu \mathrm{g} / \mathrm{mL}$, final concentration) using flow cytometry after cells were incubated for 10 minutes in the dark at room temperature. The cells showed 99\% viability.

\section{Statistical analysis}

Allele frequencies were estimated with GENEPOP program [33] while haplotypes and their frequencies were determined with the program PHASE V2.1.1 [34,35]. PHASE implements a Bayesian method of haplotype reconstruction based on genealogies reconstructed from coalescent theory under a Markov Chain Monte Carlo framework and has been shown to outperform other strategies such as the maximum likelihood expectation maximization algorithm in most cases [35].

Flow cytometric data were analyzed as a one-way ANOVA using the MIXED procedure SAS [36]. Treatment means were separated using the least square means option of SAS. Differences between treatment means were tested using Scheffe's Multiple Comparison test and statistical significance was declared at $P<0.05$.

Statistical model used: $Y_{i j}=\mu+$ genotype $_{i}+e_{i j}$

\section{Authors' contributions}

EMI-B carried out the molecular genetic studies, sequence and protein comparisons, data analysis and drafted the manuscript. J-WL and XZ conceived the study and participated in its design. $\mathrm{XZ}$ attracted funding for the project and coordinated the work. AEI carried out the flow cytometric analysis of cells and analyzed the resulting data. All authors read and approved the draft.

\section{Acknowledgements}

This research was financed by NSERC, Alberta Milk, Dairy Farmers of New Brunswick, Nova Scotia, Ontario and Prince Edward Island, Novalait Inc., Dairy Farmers of Canada, Canadian Dairy Network, AAFC, PHAC, Technology PEI Inc., Université de Montréal and University of Prince Edward Island through the Canadian Bovine Mastitis Research Network. We thank Jaime Sanchez-Dardon for technical support in flow cytometry.

\section{References}

I. Chen YC, Wang SY, King CC: Bacterial lipopolysaccharide inhibits dengue virus infection of primary human monocytes/ macrophages by blockade of virus entry via a CDI4-dependent mechanism. J Virol 1999, 73:2650-2657.

2. Haziot A, Ferrero E, Kontgen F, Hijiya N, Yamamoto S, Silver J, Stewart CL, Goyert SM: Resistance to endotoxin shock and reduced dissemination of gram-negative bacteria in CDI4-deficient mice. Immunity 1996, 4:407-4. 4I4

3. Antal-Szalmas P, Van Strijp JAG, Weersink AJL, Verhoef J, Van Kessel KPM: Quantitation of surface CDI4 on human monocytes and neutrophils. J Leukoc Biol 1997, 61:721-728.

4. Paape MJ, Lilius EM, Wiitanen PA, Kontio MP, Miller RH: Intrammary defense against infections induced by Escherichia coli in cows. Am J Vet Res 1996, 57:477-482.

5. Ulevitch RJ, Tobias PS: Receptor-dependent mechanisms of cell stimulation by bacterial endotoxin. Annu Rev Immunol 1995 , 13:437-457.
6. Arditi M, Zhou J, Dorio R, Ronge GW, Goyert SM, Kim KS: Endotoxin mediated endothelial cell injury and activation: role of soluble CDI 4. Infect Immun 1993, 6 I:3 I49-3I 56.

7. Pugin J, Schurer-Maly CC, Leturcq D, Moriarty A, Ulevitch RJ, Tobias PS: Lipopolysaccharide activation of human endothelial cells is mediated by lipopolysaccharide-binding protein and soluble CD I 4. Proc Natl Acad Sci USA 1993, 90:2744-2748.

8. Lee J-W, Paape MJ, Elsasser TH, Zhao X: Recombinant soluble CDI4 reduces severity of intramammary infection by Escherichia coli. Infect Immun 2003, 71:4034-4039.

9. Wang Y, Zarlenga DS, Paape MJ, Dahl GE: Recombinant bovine soluble CDI4 sensitizes the mammary gland to lipopolysaccharide. Vet Immunol Immunopathol 2002, 86: II5-I24.

10. Burvenich C, Van Merris V, Mehrzad J, Diez-Fraile A, Duchateau L: Severity of $E$. coli mastitis is mainly determined by cow factors. Vet Res 2003, 34:521-564.

II. Ikeda A, Takata M, Taniguchi T, Tarumi O, Sekikawa K: Molecular cloning of bovine CD 4 gene. J Vet Med Sci 1997, 59:7I5-7I9.

12. LeVan TD, Bloom JW, Bailey TJ, Karp CL, Halonen M, Martinez FD, Vercelli D: A common single nucleotide polymorphism in the CDI 4 promoter decreases the affinity of Sp protein binding and enhances transcriptional activity. J Immunol 200I, 167:5838-5844.

13. Baldini M, Lohman IC, Halonen M, Erickson RP, Holt PG, Martinznez FD: A Polymorphism in the 5 ' flanking region of the CDI4 gene is associated with circulating soluble CDI4 levels and total serum immunoglobulin E. Am J Respir Cell Mol Biol 1999, 20(5):976-983.

14. Hubacek JA, Pit'ha J, Skodova Z, Stanek V, Poledne R: C (-260)-to-T polymorphism in the promoter of the CDI4 monocyte receptor gene as a risk factor for myocardial infarction. Circulation 1999, 99:3218-3220.

15. Donati M, Berglundh T, Hytönen A-M, Hahn-Zoric M, Hanson L-Å, Padyukov L: Association of the - I59 CDI 4 gene polymorphism and lack of association of the -308 TNFA and Q55 IR IL-4RA polymorphisms with severe chronic periodontitis in Swedish Caucasians. I Clin Periodontol 2005, 32:474-479.

16. Nishimura S, Zaitsu M, Hara M, Yokota G, Watanabe M, Ueda $Y$, Imayoshi M, Ishii E, Tasaki $\mathrm{H}$, Hamasaki Y: A polymorphism in the promoter of the CDI4 gene (CDI4/-I59) is associated with the development of coronary artery lesions in patients with Kawasaki disease. J Pediatr 2003, I43:357-362.

17. Rosas-Taraco AG, Revol A, Salinas-Carmona MC, Rendon A, Caballero-Olin G, Arce-Mendoz AY: CD I4 C(-I59)T polymorphism is a risk factor for development of pulmonary tuberculosis. Infect Dis 2007, 196:1698-1706.

18. Guo QS, Xia B, Jiang Y, Morre SA, Cheng L, Li J, Crusius JBA, Pena AS: Polymorphisms of CDI4 gene and TLR4 gene are not associated with ulcerative colitis in Chinese patients. Postgrad Med J 2005, 81:526-529.

19. Kedda M-A, Lose F, Duffy D, Bell E, Thompson PJ, Upham J: The CDI4 C-I59T polymorphism is not associated with asthma or asthma severity in an Australian adult population. Thorax 2005, 60:2II-2I4.

20. Pedersen AG, Baldi P, Chauvin Y, Brunak S: The biology of eukaryotic promoter prediction: a review. Comput Chem 1999, 23:19|-207.

21. Cleveland MG, Gorham JD, Murphy TL, Toumanen E, Murphy KM: Lipoteichoic acid preparations of gram-positive bacteria induce interleukin- 12 through a CDI4-dependent pathway. Infect Immun 1996, 64(6): 1906-1912.

22. De Schepper S, De Ketelaere A, Bannerman DD, Paape MJ, Peelman L, Burvenich C: The toll-like receptor-4 (TLR-4) pathway and its possible role in the pathogenesis of Escherichia coli mastitis in dairy cattle. Vet Res 2008, 39:05.

23. Shin HJ, Lee H, Park JD, Hyun HC, Sohn HO, Lee DW, Kim YS: Kinetics of binding of LPS to recombinant CD I4, TLR4 and MD-2 proteins. Mol Cells 2007, 24: I I9-124.

24. Zhang D-E, Hetherington CJ, Tan S, Dziennis SE, Gonzalez DA, Chen $\mathrm{H}-\mathrm{M}$, Tenen DG: Sp I is a critical factor for the monocytic specific expression of human CDI4. J Biol Chem 1994, 269: I | 425-I| 434.

25. Liu S, Shapiro RA, Nie S, Zhu D, Vodovotz Y, Billiar TR: Characterization of rat CD I 4 promoter and its regulation by transcription factors API and Sp family proteins in hepatocytes. Gene 2000, 250: | $37-147$ 
26. Matsuura K, Ishida T, Setoguchi M, Higuchi Y, Akizuki S, Yamamoto S: Identification of a tissue-specific regulatory element within the murine CDI 4 gene. J Biol Chem 1992, 267:2 I787-2 I794.

27. Xing X, Wang SC, Xia W, Zou Y, Shao R, Kwong KY, Yu Z, Zhang S, Miller S, Huang L, Hung MC: The ets protein PEA3 suppresses HER-2/neu over expression and inhibits tumorigenesis. Nat Med 2000, 6: 189-195.

28. Jian J-L, Zhu C-S, Xu Z-W, Ouyang W-M, Ma D-C, Zhang Y, Chen LJ, Yang A-G, Jin B-Q: Identification and characterization of the CD226 gene promoter. J Biol Chem 2006, 28 I:2873I-28736.

29. Amills M, Sulas C, Sanchez A, Bertoni G, Zanoni R, Obexer-Ruff G: Nucleotide sequence and polymorphism of the caprine major histocompatibility complex class II DQAI (CahiDQAI) gene. Mol Immunol 2005, 42:375-379.

30. Kijas JW, Menzies M, Ingham A: Sequence diversity and rates of molecular evolution between sheep and cattle genes. Anim Genet 2005, 37:171-174.

31. Kumar S, Tamura K, Nei M: MEGA3: Integrated Software for Molecular Evolutionary Genetics Analysis and Sequence Alignment Briefings. Bioinformatics 2004, 5:150-163 [http:// www.megasoftware.net/].

32. Schug J, Overton GC: TESS: Transcription Element Search Software. Technical Report CBIL-TR-I997-I00I-v0.0 I997 [http:// www.cbil.upenn.edu/cgi-bin/tess/tess/]. Computational Biology and Informatics Laboratory, School of Medicine, University of Pennsylvania

33. Raymond M, Rousset F: GENEPOP: Population genetics software and ecumenicism. J Hered 200I, 86:248-249 [http://gene pop.curtin.edu.au/].

34. Stephens M, Donnelly P: A comparison of Bayesian methods for haplotye reconstruction. Am J Hum Genet 2003, 73:1 I62-1 I69.

35. Stephens M, Smith NJ, Donnelly P: A new statistical method for haplotype reconstruction from population data. Am J Hum Genet 200I, 68:978-989.

36. SAS Institute: SAS User's Guide. Version 9.1 I st edition. Cary, NC, USA: SAS Institute Inc; 2003.

Publish with Bio Med Central and every scientist can read your work free of charge

"BioMed Central will be the most significant development for disseminating the results of biomedical research in our lifetime. "

Sir Paul Nurse, Cancer Research UK

Your research papers will be:

- available free of charge to the entire biomedical community

- peer reviewed and published immediately upon acceptance

- cited in PubMed and archived on PubMed Central

- yours - you keep the copyright 